\title{
Exhaled nitric oxide is reduced in infants with cystic fibrosis
}

\author{
H E Elphick, E A G Demoncheaux, S Ritson, T W Higenbottam, M L Everard
}

\begin{abstract}
Background-Exhaled nitric oxide levels are low in patients with cystic fibrosis (CF), despite the chronic inflammation present in the airways. This study aimed to determine whether levels of exhaled nitric oxide were reduced prior to the onset of respiratory symptoms in infants with CF.

Methods-The levels of exhaled nitric oxide were measured using a chemiluminescence analyser in five infants with $\mathrm{CF}$ and 11 healthy control subjects, both groups having a mean age of $\mathbf{4 8 . 6}$ days.

Results-Mean levels of exhaled nitric oxide were significantly lower in infants with CF than in the control group (4.9 ppb $v 12.1 \mathrm{ppb} ; \mathrm{p}=0.01$ ).

Conclusions-This finding may be the key to understanding the inflammatory processes in early cystic fibrosis and may lead to novel treatment approaches.

(Thorax 2001;56:151-152)
\end{abstract}

Keywords: cystic fibrosis; nitric oxide; paediatrics

Cystic fibrosis (CF) is one of the most prevalent fatal hereditary diseases in the white population. Chronic progressive lung disease is the major cause of morbidity and mortality. Factors underlying the initiation of lung disease in infants with CF are poorly understood, but it has been suggested that neutrophil inflammation is present before bacterial infection. ${ }^{1}$ The mechanism for this is unclear.

Exhaled nitric oxide (eNO) has been found to be increased in inflammatory diseases of the airways such as asthma; however, despite the chronic inflammation present in the airway of symptomatic patients with $\mathrm{CF}$, eNO levels are low. ${ }^{2}$

We aimed to investigate levels of eNO in very young infants with CF in the first few weeks of life, immediately after being diagnosed on neonatal screening, before the onset of respiratory symptoms.

\section{Methods}

Infants with $\mathrm{CF}$ were diagnosed using a positive neonatal screening test with immunoreactive trypsinogen. They were studied as early as possible, before the onset of any clini-

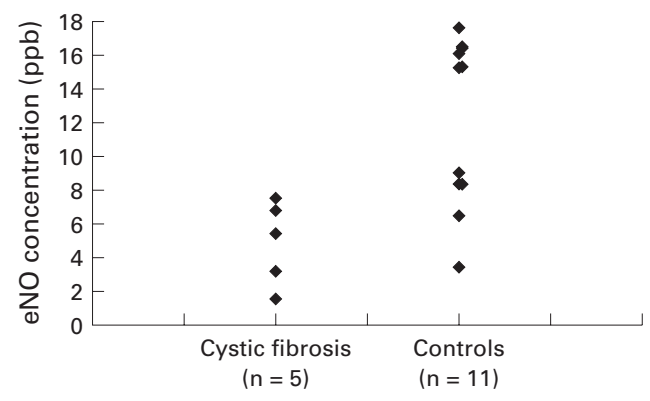

Figure 1 Exhaled nitric oxide (eNO) concentrations (ppb) in infants with cystic fibrosis (CF) and healthy controls. eNO levels are significantly lower in the $C F$ group $(p=0.01)$.

cal evidence of airway infection. Healthy control infants with no personal or family history of atopy and no previous history of any respiratory illness were studied for comparison.

A customised offline sampling system developed for infants in previous studies was used. This involved a face mask being placed over the infant's mouth and nose which provided a tight seal, and this was connected to a one way, nonrebreathing valve. The infants inhaled nitric oxide free medical air, and mixed expired air was collected into a reservoir bag (Hans Rudolph Inc) during 10 seconds of tidal breathing. The bag was then sealed with a three way tap. Three samples were taken from each infant within a time period of 20 minutes. Nitric oxide was analysed by a chemiluminescence analyser (Model Mk2B, GlaxoWellcome, UK) and the mean value of the three samples was calculated.

Five infants with $\mathrm{CF}$ were analysed at a mean age of 48.6 days (range 18-82) and 11 control subjects at a mean age of 48.6 days (range 23-93).

\section{Results}

There was a significant difference in eNO between infants with $\mathrm{CF}$ and the healthy control group. The mean value of eNO for the CF patients was $4.9 \mathrm{ppb}$ (range 1.6-7.5) compared with $12.1 \mathrm{ppb}$ (range 5.4-15.3) for the controls ( $p=0.01$, Mann-Whitney U test; fig 1$)$.

\section{Discussion}

The finding of lower concentrations of eNO in the CF airway has previously been attributed to diffusion impairment by mucus, or to oxidation 
of NO to nitrate by reactive oxygen species. ${ }^{3}$ The low values for eNO have been assumed therefore to be due to chronic airways inflammation.

However, recent work has suggested that there is a failure of upregulation of nitric oxide synthase II (NOS II) in patients with $\mathrm{CF}^{4}$ which may be caused by an inherent lack of gene expression related to the CFTR mutation. Our study would support this hypothesis - that is, reduced eNO levels are a primary feature of $\mathrm{CF}$ and do not occur as a result of airways inflammation.

If true, we can speculate that the failure of NO release could contribute to the pathogenesis of the airways disease. NO has bacteriostatic properties and has been shown to oppose neutrophil sequestration in the lung. ${ }^{5}$ An absence or significant reduction in release of
NO could reduce the host defences of the airways and lead to early neutrophil infiltration.

The authors thank the Action Laboratory Fund and the Astra Foundation for providing funding support for Dr H E Elphick and Miss S Ritson.

1 Khan TZ, Wagener JS, Bost T, et al. Early pulmonary inflammation in infants with cystic fibrosis. Am f Respir Crit Care Med 1995;151:1075-82.

2 Lundberg JON, Nordvall SL, Weitzberg E, et al. Exhaled nitric oxide in paediatric asthma and cystic fibrosis. Arch nitric oxide in paediatric
Dis Child 1996;75:323-6.

3 Ho LP, Innes JA, Greening AP. Nitrite levels in breath condensate of patients with cystic fibrosis is elevated in contrast to exhaled nitric oxide. Thorax 1998;53:680-4

4 Steagall WK, Elmer HL, Brady KG, et al. Cystic fibrosis transmembrane conductance regulator-dependent regulation of epithelial inducible nitric oxide synthase expression. Am F Respir Cell Mol Biol 2000;22:45-50.

5 Sato Y, van Eeden SF, English D, et al. Inhaled nitric oxide reduces the sequestration of activated polymorphonuclear leukocytes in the lung. Am $\mathcal{F}$ Respir Crit Care Med 1998;157:A351. 